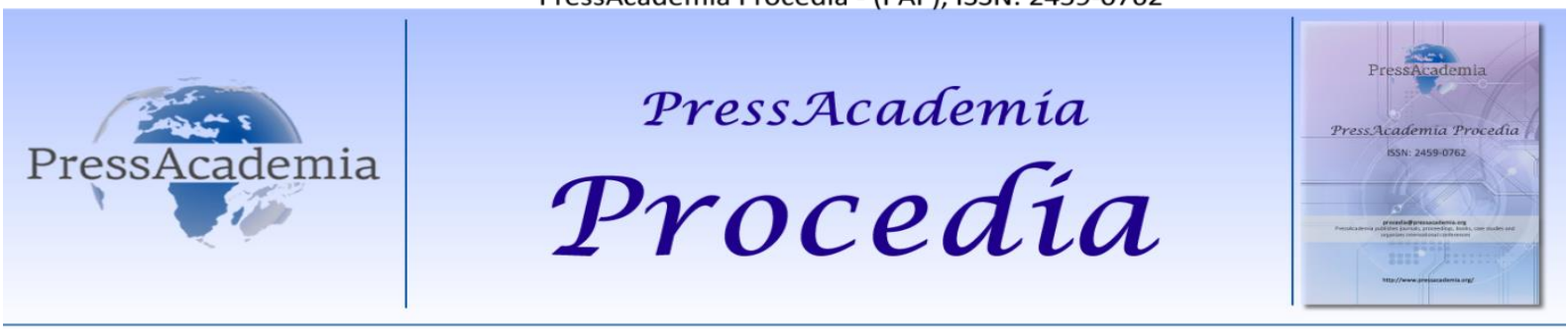

Global Business Research Congress (GBRC), May 24-25, 2017, Istanbul, Turkey.

\title{
IN TERMS OF HOSPITAL MANAGEMENT, EMPLOYEE PERCEPTION OF HOSPITAL AUTOMATION SYSTEM
}

\author{
DOI: 10.17261/Pressacademia.2017.657 \\ PAP- GBRC-V.3-2017(83)-p.770-782
}

\author{
Munevver Koca ${ }^{1}$, Yildirim Gulhan ${ }^{2}$, Salim Yilmaz ${ }^{3}$ \\ ${ }^{1}$ Okan University, mnevverkoca@yahoo.com \\ ${ }^{2}$ Okan University, Tepeören Mahallesi, 34959 Akfırat, Tuzla, ISTANBUL, yildirim.gulhan@okan.edu.tr \\ ${ }^{3}$ Okan University, Tepeören Mahallesi, 34959 Akfırat, Tuzla, ISTANBUL, salim.yilmaz@okan.edu.tr
}

\section{To cite this document}

Koca M, Y. Gulhan and S. Yilmaz (2017). In terms of hospital management, employee perception of hospital automation system.

Pressacademia Procedia (PAP), V.3, p.770-782.

Permemant link to this document: http://doi.org/10.17261/Pressacademia.2017.657

Copyright: Published by PressAcademia and limited licenced re-use rights only.

\section{ABSTRACT}

It was aimed to determine the perception levels of nurse and medical secretary-data entry staffs who working in Adana Numune Training and Research Hospital Seyhan Application Center which constitutes the health records of Health Information Systems and actively uses Hospital Information Management Systems in the study. 249 nurses and 114 medical secretaries-data entry staffs who working in the Adana Numune Training and Research Hospital Seyhan Application Center constitute the universe of research. 83 of them are nurses and 38 of them are medical secretary-data entry staffs constitute the research sample. Survey method was preferred in the research and samples were randomly selected. Cronbach's alpha test was used for survey's validity and reliability. Dependent variable is level of perception; Independent variable is demographic characteristics in the study. Evaluation of the data was done in the SPSS 18 program. As a result of the study, it was determined that the perception of the hospital automation system was higher among the data entry staffs in those who graduated from high school. It was seen that nurses thought that they did not have all the authority to use the system, that they encountered frequent problems in the system, that the problems were not resolved in a short time, that the system did not make work easier enough and did not meet expectations, The data entry staffs stated that they were educated about the subject and the nurses did not take it. Both groups found that the system was useful for patient operations and laboratory operations.

Keywords: Hospital information system, hospital staff, perception level, nurses, medical secretaries JEL Codes: 112, 119, 033

HASTANE YÖNETIMI AÇISINDAN ÇALIŞANLARDA HASTANE OTOMASYON SISTEMININ
ALGILANMASI

\section{ÖZET}

Çalışmada Sağlık Bilişim Sistemleri'nin sağlık kayıtlarını oluşturan ve Hastane Bilgi Yönetim Sistemleri'ni aktif kullanan Adana Numune Eğitim ve Araştırma Hastanesi Seyhan Uygulama Merkezi'nde çalışan hemşire ve tıbbi sekreter-veri giriş elemanlarının Hastane Bilgi Yönetim Sistemi uygulamasındaki algı düzeylerinin belirlenmesi amaçlanmıştır. Adana Numune Eğitim ve Araştırma Hastanesi Seyhan Uygulama Merkezi'nde çalışan 249 hemşire ve 114 tıbbi sekreter-veri giriş görevlisi araştırma evrenini; bu kişilerden 83'ü hemşire, 38'i tıbbi sekreter-veri giriş elemanı olmak üzere 121 kişi örneklemi oluşturmaktadır. Araştırmada anket yöntemi tercih edilmiştir ve örneklemler rastgele seçilmiştir. Anketin geçerlilik ve güvenilirliğinde Cronbach Alpa testi kullanılmıştır. Çalışmanın bağımlı değişkeni, algı düzeyi; Bağımsız değişkeni demografik özelliklerdir. Verilerin değerlendirilmesi SPSS 18 programında yapılmıştır. Çalışmanın sonucunda, hastane otomasyon sisteminin algılanmasının, veri giriş elemanları arasında, lise mezunu olanlarda daha yüksek olduğu tespit edilmiştir. Hemşireler sistem kullanımı için gereken tüm yetkilere sahip olmadığını, sistemde sık sık sorunlarla karşılaştıklarını, sorunların kısa zamanda çözülmediğini, sistemin işleri yeterince kolaylaştırmadığını ve beklentileri karşılamadığını düşünürken, veri giriş çalışanlarının ise tam tersini düşünmekte oldukları görülmüştür. Veri giriş elemanları konuyla ilgili eğitim aldıklarını, hemşireler ise almadıklarını ifade etmişlerdir. Her iki grup da sistemin hasta işlemleri ve laboratuvar işlemleri için faydalı olduğunu düşündükleri görülmüştür.

Anahtar Kelimeler: Hastane otomasyon sistemi, hastane çalışanları, algı düzeyi, hemşireler, tıbbi sekreterler JEL Kodları: I12, I19, O33 


\section{GíRiş}

Sağlık Bilişim Sistemleri (SBS), tıp alanında meydana gelen gelişmeler sonucunda ortaya çıkan veri ve bilgilerin meydana getirilmesi, şekillendirilmesi paylaşılması ve en sonunda hastaların tedavi ve şekillerinin belirlenmesi, seçilmesi ve geliştirilmesi işlemlerinin bütününe verilen isimdir. Yani SBS, hasta hakkında düşünme yöntemleri ve tedavilerin tanımlanma, seçilme ve geliştirilme yolları üzerine önemli bir çalışmadır. (1) Sağıı Bilişimi, sağlık bakım hizmetlerinin sunumu ve uygulamasında mevcut bilgi ve verilerin enformasyona dönüştürülmüş, vazgeçilmez temel bir ögesidir. Toplanan tüm verilerin etkin ve verimli bir şekilde hizmet sunumunda kullanılması da sağlık bilgi sistemlerine en doğru şekilde aktarılmasıyla mümkündür. Hızlı ve etkin sağlık hizmeti sunumunda kaliteli bilgilerin, zamanında, tam, doğru ve uygun kullanım koşullarında hazırlanması, sağlık bilişiminin etkinliğini bir kat daha artırmaktadır. (2)

Hastane bilgi yönetim sistemi de hastane işletmelerinin çeşitli düzeylerdeki karar alıcılarına yardımcı olmak amacıyla, bilgi toplama ve bilgi yayma fonksiyonlarını üstlenen, değişik kaynaklardan elde edilen verileri bütünleyebilen bir sistem olarak, hizmetlerin bilgisayar aracılığı ile gerçekleştirilmesi; elektronik ortamda bilgi alışverişinin otomatik olarak yapılması; tıbbifinansal/mali hizmetler açısından ortaya çıkan ayrıntılı bilgilerin bilgisayara dayalı bir enformasyon sistemi ile kaydedilerek bilgiye dönüştürülmesi olarak tanımlanmaktadır. Hastane bilgi yönetim sistemi, kısmen bilgisayarlarla, temel olarak insanla ve onun sosyal davranışıyla ilgili olduğu için, hastanenin sosyo-teknik alt sistemidir(3).

Hastane bilgi yönetim sisteminin işleyişi, hastanın herhangi bir sağlık kuruluşuna başvurduğu zaman otomatik olarak başlar. Hastanın sağlık kuruluşuna adım atması ile birlikte fiziki muayene bilgileri, doktor tarafından istenen laboratuvar testleri ve sonuçları, bilgisayar ortamında girişleri yapılarak önceki test sonuçları ile birlikte değerlendirilir. Doktora ve uzmana telefonla aynı zamanda bilgiler danışılır. Elde edilen bilgiler ileride tekrar kullanılmak üzere ana bellekte depolanır. Böylece hasta ile ilgili kayıtlara istenildiği zaman ulaşılabileceği gibi, hastaya uygulanacak olan medikal tedavide hangi ilaçlara karşı alerjisinin olduğu gibi bilgiler belirlenmiş olmaktadır. Otomatik olarak verilen hizmetin maliyeti, geri ödemesi ortaya konulmuş olur(4).

HBYS'nin işlemesini ekonomik ve teknolojik sorunlar etkileyebilir. Ancak bunların yanı sıra organizasyonel ve davranışsal sorunlar da HBYS benimsenmesi geciktirebilmektedir. Joanne ve arkadaşları bu sorunları, çevresel düzeyde ve tüketicilere odaklı bireysel düzeyde ele almışlardır. Yine bu çalışmada sağlık çalışanlarının HBYS'yi benimsemesinin karşısındaki engelleri, kişisel sağlık kayıtlarının; çevresel engelleri, bireysel engelleri ve yapılanışı olarak sınıflandırmışlardır. Bu konuda yapılacak eğitim ve araştırmalar kişisel sağlık kayıtlarının benimsenmesini kolaylaştırabileceği sonucuna varmışlardır(5).

Bu çalışmada belirtilen çerçevede SBS'nin sağlık kayıtlarını oluşturan ve HBYS'yi aktif kullanan Adana Numune Eğitim ve Araştırma Hastanesi Seyhan Uygulama Merkezi'nde çalışan hemşire ve tıbbi sekreter-veri giriş elemanlarının HBYS uygulamasındaki algı düzeyinin belirlenmesi amaçlanmıştır.

\section{LITERATURE INCELEMESi}

Tıp Bilişimi, bilgi teknolojilerini kullanarak, tıbbi çalışma, eğitim, iletişim, veri ve bilgi toplama, veri ve bilgi işleme, bilgiyi yönetme, tıbbi karar verme ve bilimsel çözümleme yöntemlerinin içeren bir bilim dalıdır (6). Sağlık Bilgi Teknolojileri, elektronik sağlık kayıtları, kişisel sağlık kayıtları, sağlık bilgi transferi, mobil sağlık ve sağlığı destekleyen diğer teknolojileri içerir (7). ABD'de ulusal sağlığın iyileştirilmesi için sağlık sisteminin dört ana etkeninin güçlendirilmesi gerektiği vurgulanmaktadır. Bunlar: kişisel sağlık yönetimi, sağıık hizmetleri sunumu, kamu sağlığı ve sağlıkla ilgili araştırmalardır. Sağlık sektörünün birçok önlenebilir eksiklikleri sonucu gelişen düşük kalite; veri, bilgi ve belgeye tam erişilememesi nedeniyle gelişmektedir (8). E-Sağlık sağlık sektöründe hem yerel ve ulusal düzeyde klinik, eğitim, araştırma ve idari amaçlar için elektronik bilgi ve iletişim teknolojisinin (ICT) kullanımınıkapsayan bir terimdir. SBS; Bilgi ve belgelerin hacmi ve karmaşıklığı nedeniyle sağlık kayıtlarını bilgi yönetimi araçlarının desteği olmadan en iyi şekilde yönetmek sağlık çalışanları için vazgeçilmez hale gelmiştir (9). Türkiye'de e-Sağlık projesi ile sağlık veri standardizasyonunun sağlanması, veri analiz desteği ve karar destek sistemleri oluşturulması, e-sağıı paydaşları arasında veri akışının hızlandırılması, elektronik kişisel sağ ıık kayıtlarının oluşturulması, kaynak tasarrufunun sağlanması ve verimliliğin artırılması, e-sağılı girişim süreçlerinin koordine edilmesi, bilimsel çalışmalara destek verilmesi, e-sağlık kavramının ulusal anlamda benimsenmesinin hızlandırılması amaçlanmıştır $(10,11)$

Sağlıkta Dönüşüm Programı'nın temel bileşenlerinden biri olan Ulusal Sağlık Bilgi Sistemi (USBS), dönüşüm projesi kapsamında uygulamaya konulan reformların en önemli aşamalarından biridir. USBS tüm vatandaşları kapsayan, her bireyin kendi bilgilerine erişebildiği, bireyin doğumundan önce başlayıp tüm yaşamı boyunca sağlığıyla ilgili verilerden oluşan işlevsel bir veri tabanının, yüksek bant genişlikli ve tüm ülkeyi kapsayan bir iletişim omurgasında paylaşılması ve tele-tıp uygulamalarına varan teknolojilerin mesleki pratikte kullanılmasını temel alan elektronik kayıt sistemidir. Bu sistem ayrıca sağılık hizmeti sunan tüm kurum ve kuruluşların insan gücü, taşınır, taşınmaz, idari ve mali verilerini de kayıt altına alacak şekilde tasarlanmıştır (10). 
Sağlık Bakanlığı WEB Uygulamaları; Çekirdek Kaynak Yönetimi Sistemi (ÇKYS-TSiM), Elektronik Belge Yönetim Sistemi, Elektronik Tüberküloz Yönetim Sistemi(e-TYS), Doktor Bilgi Bankası, Döner Sermaye Bütçe Uygulaması, Hasta Hakları, Hastane Enfeksiyonları, İşç Sayısı Tespit Sistemi, Karar Destek Sistemleri ( İş-Zekası), Karar Destek Sistemleri (Sağılık.NET 2), Özürlüler Veri Bankası, Personel Bilgi Sistemi (PBS), Programları İzleme Değerlendirme Sistemi, Tek Düzen Muhasebe Sistemi (TDMS), Türkiye Diyaliz Bilgi Yönetim Sistemi, Türkiye Yoğun Bakım İzleme Sistemi, Türkiye Organ ve Doku Bağışı Bilgi Sistemi, Ulusal Organ Bilgi Sistemi, Yeni Doğan İşitme Taraması, Yeşil Kart Bilgi Sistemi, Sosyal Tesis Muhasebe Takip Sistemi içerir(11).

Tıp Bilişiminin Alanları aşağıda sayılan alanlardan oluşmaktadır: $(6,12,13)$

- $\quad$ Klinik Bilgi Sistemleri(HIS, LIS, RIS)

- Tıbbi Karar Sistemleri

- $\quad$ Tıbbi Kayıt Sistemleri

- $\quad$ Entegre Akademik BYS

- Hastane Yönetim Sistemleri

- $\quad$ Bilgisayar Destekli Tıp Eğitimi

- $\quad$ Sağlık Bakımı Uzman Sistemleri

- Görüntü Işleme ve Analizi

- $\quad$ Sinyal Analizi

- Hemşirelik Bilgi Sistemleri

- $\quad$ Idari Karar Sistemleri

- $\quad$ Tıbbi Bilgi Ağı(Teletıp, Internet)

- Sağlık Bilgi Standartları

- $\quad$ Sağlık Bilişimi Eğitimi

Klinik bilgi sistemleri; elektronik sağlık kayıtları, klinik karar destek sistemleri, hemşire bilgi sistemleri, görüntü yönetim ve depolama sistemleri, klinik iletişim sistemleri, teletıp, vaka bilişimi, sanal gerçeklik uygulamaları, akıllı kart uygulamaları, hastane bilgi sistemleri, standartlar ile klinik kılavuzlar ve bakım haritaları gibi bileşenlerden oluşmaktadır (14). Klinik Karar Destek Sistemleri; hekimlerin hastalarla ilgili en iyi kararı verebilmesi için destek sağlayan bilişim sistemi uygulamalarıdır. Bazıları bu sistemlerin hekimlerin yerini alacağını düşünmelerine rağmen, gerçekte bu sistemler en güncel bilgileri hekimlerin emrine sunarak karar vermelerine yardımcı olmak maksadıyla tasarlanmaktadır(15). Hemşirelik bilgi sistemi, hastane bilgi sistemlerinde; bilgiye nasıl ulaşılacağı, verilerin nasıl elde edileceği, nasıl kullanılacağı, nasıl kayıt altına alınacağı ve ne şekilde saklanacağını tariflemektedir. Hemşirelik bilgi sisteminin iletişimin geliştirilmesi, karar verme işleminin desteklenmesi, yeni bilgilerin ortaya konulması, etkin, etkili ve kaliteli sağlık bakımının sunulması, hasta beklentilerinin karşılanması, elde edilen bilginin diğer sağlık çalışanları ve kurumları arasında paylaşılması yönünde büyük fırsatlar sağlamaktadır (3).

Laboratuvar Bilgi Sistemleri; Laboratuvarların artan iş yükü ve sorumluluğu çok büyük miktarda laboratuvar bilgisini toplamayı, özet halinde ve belli bir biçimde hazırlanmasını ve olabildiğince hızlı bu bilgilerin hekimlere ulaşmasını sağlamayı zorlaştırmaktadır. Bu gibi problemleri gidermek için bilgisayarlı sistemlere ve on-line elektronik işlem donanımlarına olan talep artmaktadır (16). Radyoloji bilgi sistemleri; randevu, tetkiklerin kabul ve onay işlemleri, kayıt, raporlama süreci, cihazlarda iş listesinin oluşturulması, veri provizyonu ve yakın zamanlarda da ses tanıma gibi işlevlere karşılık gelecek şekilde düzenlenir. Radyoloji bilgi sistemi, yüksek kayıt kapasitesi isteyen medikal görüntülerin saklanarak, istenildiğinde çok hızlı bir şekilde erişimin sağlanabildiği bir bilgi yönetim sistemidir (17).

Eczane bilgi sistemleri (EBS) hasta bakımında ilaç kullanımı, ilaç stok ve yönetimi faaliyetlerini kapsamaktadır. Hastane eczanelerinde geniş bir bilgi işlem ihtiyacı mevcuttur. Illaçların siparişi, stoklanması ve dağıtımının dikkatli biçimde denetimi, azda olsa tıbbi hatalardan kaçınmak üzere güvenli kayıtlar tutmak ve saklamak bir zorunluluk olarak karşımıza çıkmaktadır. Aynı zamanda muhasebe ve karlıık hesapları için de bilgi sistemine ihtiyaç vardır (17). Hasta kayıt kabul, taburcu ve transfer işlemleri; Hasta kayıt kabul, taburcu ve transfer işlemleri (Registration-Admission Discharge and Transfer- R-ADT) sistemi idari sistemler için bir örnektir. Hastane bilgi sistemlerinde yer alan bu bölüm temel bir modülde hastanenin tüm bölümleriyle ilgili yeni hasta kabulü için bir kayıt oluşturmak üzere kullanılan ilk veri dizisini toplar ve taburculuktan sonraki 
veriler ve işlevleri bu uygulamaya ekler. Hastane bilgi sistemi aşağıdaki işlevleri gerçekleştirmek için R-ADT uygulamasına bağlanır (16):

1- Kurumsal hasta indeksini oluşturmak ve güncelleştirmek,

2- Kurumda gerekli olan sayım görüntüleri ve ilişkili raporlarını oluşturmak,

3- Uygun olduğunda kullanım protokolleri başlatmak,

4- Otomatik kayıt izlem modülleri aracılığıyla hasta kaydını yeniden elde etmek, kopyaları / suretleri tebliğ etmek ve erken raporlar için veri sağlamak,

5- Klinik randevuları kolaylaştırmak için veriyi poliklinik listeleme sistemlerine aktarmak,

6- Bağlantı oluşturulduysa hastayla ilgili veri aktarımı için iletişim sistemleri yoluyla hekim muayene odalarına ve diğer sağlık birimlerine bağlantı sağlamak.

7- Hasta kabullerin izlenmesi ve tercihli hasta kabulünün listelenmesi, hastane sayımlarındaki günlük dalgalanmaları azaltmaya ve esnek personel sistemlerinde çalışmanın geliştirilmesine yardım eder.

Sosyal boyut içerisinde yer alan önemli parametrelerden birisi de bilgi güvenliğinin yasal boyutudur. Gelişmiş ülkelerde ülke çapında tüm kurumları bağlayan düzenleyici bilgi güvenliği yasaları mevcuttur. Ülkemizde, düzenleyici mevzuat konusunda çalışmalar devam etmektedir (18).

1- Uluslar arası düzenlemelerde 2008 yılında yayımlanan ve sağlık sektörü için bilgi güvenliği esaslarını bizlere sunan yeni ISO standardı; ISO 27799:2008 (Sağlık Bilgileri - Sağlıkta ISO/IEC 27002 bilgi güvenliği yönetimi) oldukça önemlidir. ISO 27799:2008, bilgilerin şekillendirilmesi, saklanması ve paylaşılması aşamasında gerekli olan tüm tedbirlerin alınması ve güvenlik altında tutulması için detaylı standartlar da içermektedir.

2- Bilgi Toplumu Stratejisi Eylem Planı 87 numaralı madde bilgi güvenliği ile ilgili yasal düzenlemeleri içermektedir. Bu maddeye göre ülke güvenliğini ilgilendiren bilgilerin elektronik ortamda gerekli şekillerde korunması ve devletin bilgi güvenliği sistemlerinin geliştirilmesi amacına uygun yasal altyapı düzenlemelerin yapılması ve bu düzenlemelerin uygulamaya konulması hedefi belirtilmiştir.

3- 25897 sayılı Resmi Gazete'de yayınlanan E-dönüşüm Türkiye Projesi Birlikte Çalışabilirlik Esasları Rehberi'nin dört numaralı "güvenlik" başlığı altında, bilgi güvenliği yönetim sistemi, ortak kriterler standardı, elektronik imza ve kriptografi ile ilgili birlikte çalışabilirlik esasları yer almaktadır.

4- T.C. Başbakanlık Personel ve Prensipler Genel Müdürlüğü tarafından hazırlanan ve 17 Şubat 2003 tarihinde imzalanan "Bilgi Sistem ve Ağları için Güvenlik Kültürü" konulu Başbakanlık Genelgesi, OECD Bilgi Güvenliği ve Kişisel Mahremiyet Çalışma Grubu tarafından hazırlanmış olan rehberdir.

\section{VERI VE YÖNTEM}

Çalışmamızda hastane bilgi sistemleri ve otomasyon uygulamalarının ve Adana Numune Eğitim ve Araştırma Hastanesi Seyhan Uygulama Merkezi'nde çalışan hemşire, tıbbi sekreter ve veri giriş elemanlarının HBYS konusundaki algılarının belirlenmesi amaçlanmaktadır. Çalışmamız Adana Numune Eğitim ve Araştırma Hastanesi Seyhan Uygulama Merkezi'nde görevli hemşireleri, tıbbi sekreterleri-veri giriş görevlilerini kapsamaktadır. Anket yöntemi tercih edilmiş olup, Adana Numune Eğitim ve Araştırma Hastanesi Seyhan Uygulama Merkezi'nde görevli 249 hemşire ve 114 tıbbi sekreter-veri giriş görevlisinin üçte biri çalışmanın örneklemine dahil edilmiştir. Buna göre Tablo 1'de görüldüğü gibi 83 hemşire ve 38 tıbbi sekreter-veri giriş elemanı olmak üzere 121 çalışana anket uygulanmıştır Örneklem rastegele seçilmiştir. Anketteki faktörlerin güvenilirliğini ölçmek için Cronbach'ın Alpha katsayısı kullanılmıştır. Bu bağlamda anket 20 kişiye uygulanarak ankete ilişkin likert ölçeği ile puanlama yoluyla ölçülen 20 soru (değişkenler) için geçerlilik ve güvenilirlik analizi yapılmıştır. Anket sorularının geçerliliği ve güvenilirliği için yukarıda ifade edilen Cronbach Alpha test istatistiği kullanılmıştır. Bu çalışmadaki güvenilirlik kat sayısı $\alpha=0.854$ olarak bulunmuştur, bu sonuca göre anket yüksek derecede güvenilir olarak kabul edilmiştir.

Verilerin analizinde SPSS 18 paket programı kullanılmıştır. Analizde tanımlayıcı analiz yöntemleri ile birlikte;Unvan ile cinsiyet, yaş, öğrenim durumu, hastanedeki hizmet süresi, işe girişinizden itibaren toplam hizmet süresi, çalıştığınız birim arasındaki ilişki kikare analizi; Unvan ile çalışılan birim arasındaki ilişki kikare analizi ile; Unvan, cinsiyet ve çalışılan servis ile "Hastane Otomasyon Sisteminin Çalışanlar Açısından Algılanması" ölçeğinden alınan puan, arasındaki ilişki bağımsız $t$ testi ile;Yaş ile "Hastane Otomasyon Sisteminin Çalışanlar Açısından Algılanması" ölçeğinden alınan puan, arasındaki ilişki Kruskal-Wallis Testiyle;Öğrenim durumu, hastanedeki hizmet süresi, toplam hizmet süresi ile "Hastane Otomasyon Sisteminin Çalışanlar Açısından Algılanması" ölçeğinden alınan puan, arasındaki ilişki Kruskal-Wallis Testi ile Anova Testiyle; Araştırmaya katılanların "Hastane Otomasyon Sisteminin Çalışanlar Açısından Algılanması" sorularına "katılma/katılmama" durumları pareto analizi ile incelenmiştir. 
Tablo 1: Araştırmanın Evreni ve Örneklemi

\begin{tabular}{|l|c|c|}
\hline & \multicolumn{2}{|c|}{ HEMŞiRE } \\
\hline Servis & Evren & Örneklem \\
\hline Kardiyoloji Servisi & 32 & 11 \\
\hline Koroner Yoğun Bakım 1 & 20 & 7 \\
\hline Koroner Yoğun Bakım 2 & 16 & 5 \\
\hline Koroner Yoğun Bakım 3 & 11 & 4 \\
\hline Kalp ve Damar Cerrahi Servisi & 17 & 6 \\
\hline $\begin{array}{l}\text { Kalp ve Damar Cerrahi Yoğun } \\
\text { Bakım }\end{array}$ & 13 & 4 \\
\hline Yanık Servisi & 9 & 3 \\
\hline Yanık Yoğun Bakım & 9 & 3 \\
\hline Acil Servis: & 13 & 4 \\
\hline Ameliyathane: & 30 & 10 \\
\hline Anjio Birimi: & 12 & 4 \\
\hline Anjio Kliniği & 6 & 2 \\
\hline $\begin{array}{l}\text { Cerrahi Servisler (Genel, } \\
\text { Ortopedi, Plastik, Üroloji, KBB) }\end{array}$ & 25 & 8 \\
\hline Poliklinikler & 30 & 10 \\
\hline İdari Kat & 6 & 2 \\
\hline Toplam & $\mathbf{2 4 9}$ & $\mathbf{8 3}$ \\
\hline
\end{tabular}

\begin{tabular}{|l|c|c|}
\hline \multicolumn{1}{|c|}{ Servis } & \multicolumn{2}{c|}{ Tıbbı Sekreter-Veri Giriş } \\
\hline Poliklinikler & Evren & Örneklem \\
\hline $\begin{array}{l}\text { Servislerde (Her } \\
\text { Serviste 2 Veri Giriş } \\
\text { Elamanı) }\end{array}$ & 32 & 20 \\
\hline $\begin{array}{l}\text { İdare (Özlük, Evrak } \\
\text { Kayıt,Bilgi İşlem) }\end{array}$ & 10 & 3 \\
\hline Laboratuar & 3 & 1 \\
\hline Eczane & 6 & 2 \\
\hline Acil & 3 & 1 \\
\hline Toplam & $\mathbf{1 1 4}$ & $\mathbf{3 8}$ \\
\hline
\end{tabular}

Hastane Otomasyon Sistemi konusundaki düşünceleri ve algı düzeylerini ölçen sorular bağımlı değişkeni; cinsiyet, yaş, görev, öğrenim durumu, hastanedeki hizmet süresi, toplam hizmet süresi, çalışılan servis bağımsız değişkenleri oluşturmuştur. Araştırmanın hipotezi şudur: "Adana Numune Eğitim ve Araştırma Hastanesi Seyhan Uygulama Merkezi'nde kullanılan bilgi ve iletişim sistemlerine bakış açısında; ünvana göre fark yoktur."

\section{BULGULAR VE TARTIŞMA}

\subsection{Demografik Özellikler}

Tablo 2'de görüldüğü gibi araştırmaya katılan hemşirelerin $\% 95,18^{\prime} \mathrm{i}$, veri giriş elemanlarının $\% 81,58$ si kadındır. Yaş dağılımına bakıldığında, hemşirelerin \%61,45'i, veri giriş elemanlarının \%42,86'sı 35-44 yaş arasında, Mezuniyet durumuna göre hemşirelerin \%56,63'ü lisans mezunu, veri giriş elemanlarının 52,63'ü lise mezunudur. Hizmet süresine göre; hemşirelerin \%46,99'u, veri giriş elemanlarının 42,10'u 1-4 yıl hizmet süresine sahiptir. Toplam hizmet süresine göre; hemşirelerin \%66,27'si 13 yıl ve üzeri, veri giriş elemanlarının 35,14'u 1-4 yıl, \%35,14'i 5-8 yıl hizmet süresine sahiptir.

Tablo 2: Araştırmaya Katılan Hemşire ve Veri Giriş Elemanlarının Tanıtıcı Özellikleri

\begin{tabular}{|c|c|c|c|c|c|}
\hline & & \multicolumn{2}{|c|}{ Unvan } & \multirow[b]{2}{*}{ Toplam } & \multirow{2}{*}{$\begin{array}{c}\text { Kikare } \\
\text { p }\end{array}$} \\
\hline & & Hemşire & Veri Giriş Elemanı & & \\
\hline \multirow{2}{*}{ Cinsiyet } & Kadın & $\begin{array}{c}79 \\
95,18 \%\end{array}$ & $\begin{array}{c}31 \\
81,58 \%\end{array}$ & $\begin{array}{c}110 \\
90,91 \%\end{array}$ & \multirow[t]{3}{*}{$\begin{array}{c}5,835 \\
0,16\end{array}$} \\
\hline & Erkek & $\begin{array}{c}4 \\
4,82 \%\end{array}$ & $\begin{array}{c}7 \\
18,42 \%\end{array}$ & $\begin{array}{c}11 \\
9,09 \%\end{array}$ & \\
\hline Toplam & & $\begin{array}{c}83 \\
100,00 \%\end{array}$ & $\begin{array}{c}38 \\
100,00 \%\end{array}$ & $\begin{array}{c}121 \\
100,00 \%\end{array}$ & \\
\hline Yaş & $\begin{array}{l}\text { 45- } 54 \text { ve } \\
\text { üzeri }\end{array}$ & $\begin{array}{c}14 \\
16,87 \%\end{array}$ & $\begin{array}{c}6 \\
17,14 \%\end{array}$ & $\begin{array}{c}20 \\
16,95 \%\end{array}$ & $\begin{array}{l}4,567 \\
0,102\end{array}$ \\
\hline
\end{tabular}




\begin{tabular}{|c|c|c|c|c|c|}
\hline & $35-44$ & $\begin{array}{c}51 \\
61,45 \%\end{array}$ & $\begin{array}{c}15 \\
42,86 \%\end{array}$ & $\begin{array}{c}66 \\
55,93 \%\end{array}$ & \\
\hline & $25-34$ & $\begin{array}{c}18 \\
21,69 \%\end{array}$ & $\begin{array}{c}14 \\
40,00 \%\end{array}$ & $\begin{array}{c}32 \\
27,12 \%\end{array}$ & \\
\hline Toplam & & $\begin{array}{c}83 \\
100,00 \% \\
\end{array}$ & $\begin{array}{c}35 \\
100,00 \% \\
\end{array}$ & $\begin{array}{c}118 \\
100,00 \%\end{array}$ & \\
\hline \multirow{3}{*}{$\begin{array}{l}\text { Öğrenim } \\
\text { Durumu }\end{array}$} & $\begin{array}{l}\text { Lise } \\
\text { Mezunu }\end{array}$ & $\begin{array}{c}7 \\
8,43 \% \\
\end{array}$ & $\begin{array}{c}20 \\
52,63 \% \\
\end{array}$ & $\begin{array}{c}27 \\
22,31 \% \\
\end{array}$ & \multirow[t]{4}{*}{$\begin{array}{l}32,83 \\
0,000\end{array}$} \\
\hline & $\begin{array}{l}\text { Ön Lisan } \\
\text { Mezunu }\end{array}$ & $\begin{array}{c}29 \\
34,94 \%\end{array}$ & $\begin{array}{c}12 \\
31,58 \%\end{array}$ & $\begin{array}{c}41 \\
33,88 \%\end{array}$ & \\
\hline & $\begin{array}{l}\text { Lisans } \\
\text { Mezunu }\end{array}$ & $\begin{array}{c}47 \\
56,63 \% \\
\end{array}$ & $\begin{array}{c}6 \\
15,79 \% \\
\end{array}$ & $\begin{array}{c}53 \\
43,80 \% \\
\end{array}$ & \\
\hline \multicolumn{2}{|l|}{ Toplam } & $\begin{array}{c}83 \\
100,00 \% \\
\end{array}$ & $\begin{array}{c}38 \\
100,00 \% \\
\end{array}$ & $\begin{array}{c}121 \\
100,00 \% \\
\end{array}$ & \\
\hline \multirow{4}{*}{$\begin{array}{l}\text { Kurumda } \\
\text { Hizmet } \\
\text { Süresi }\end{array}$} & 1-4 yıl & $\begin{array}{c}39 \\
46,99 \% \\
\end{array}$ & $\begin{array}{c}16 \\
42,10 \% \\
\end{array}$ & $\begin{array}{c}55 \\
45,45 \% \\
\end{array}$ & \multirow[t]{5}{*}{$\begin{array}{l}0,947 \\
0,814\end{array}$} \\
\hline & $5-8$ yıl & $\begin{array}{c}24 \\
28,92 \%\end{array}$ & $\begin{array}{c}13 \\
34,21 \%\end{array}$ & $\begin{array}{c}37 \\
30,58 \% \\
\end{array}$ & \\
\hline & $9-12$ yıl & $\begin{array}{c}14 \\
16,87 \%\end{array}$ & $\begin{array}{c}5 \\
13,16 \%\end{array}$ & $\begin{array}{c}19 \\
15,70 \% \\
\end{array}$ & \\
\hline & $\begin{array}{l}13 \text { yıl ve } \\
\text { üzeri }\end{array}$ & $\begin{array}{c}6 \\
7,22 \% \\
\end{array}$ & $\begin{array}{c}4 \\
10,53 \% \\
\end{array}$ & $\begin{array}{c}10 \\
8,26 \% \\
\end{array}$ & \\
\hline \multicolumn{2}{|l|}{ Toplam } & $\begin{array}{c}83 \\
100,00 \%\end{array}$ & $\begin{array}{c}38 \\
100,00 \%\end{array}$ & $\begin{array}{c}121 \\
100,00 \%\end{array}$ & \\
\hline \multirow{4}{*}{$\begin{array}{l}\text { Toplam } \\
\text { Çalışma } \\
\text { Süresi }\end{array}$} & 1-4 yıl & $\begin{array}{c}11 \\
13,25 \% \\
\end{array}$ & $\begin{array}{c}13 \\
35,14 \% \\
\end{array}$ & $\begin{array}{c}24 \\
20,00 \% \\
\end{array}$ & \multirow[t]{5}{*}{$\begin{array}{c}26,737 \\
0,000\end{array}$} \\
\hline & $5-8$ yıl & $\begin{array}{c}8 \\
9,64 \% \\
\end{array}$ & $\begin{array}{c}13 \\
35,14 \% \\
\end{array}$ & $\begin{array}{c}21 \\
17,50 \% \\
\end{array}$ & \\
\hline & 9-12 yıl & $\begin{array}{c}9 \\
10,84 \% \\
\end{array}$ & $\begin{array}{c}4 \\
10,81 \% \\
\end{array}$ & $\begin{array}{c}13 \\
10,74 \% \\
\end{array}$ & \\
\hline & $\begin{array}{l}13 \text { yıl ve } \\
\text { üzeri }\end{array}$ & $\begin{array}{c}55 \\
66,27 \% \\
\end{array}$ & $\begin{array}{c}7 \\
18,92 \% \\
\end{array}$ & $\begin{array}{c}62 \\
51,67 \% \\
\end{array}$ & \\
\hline \multicolumn{2}{|l|}{ Toplam } & $\begin{array}{c}83 \\
100,00 \%\end{array}$ & $\begin{array}{c}37 \\
100,00 \%\end{array}$ & $\begin{array}{c}120 \\
100,00 \%\end{array}$ & \\
\hline
\end{tabular}

Tablo 3: Araştırmaya Katılan Hemşire Ve Veri Giriş Elemanlarının Çalıştığı Birime Göre Dağılımı

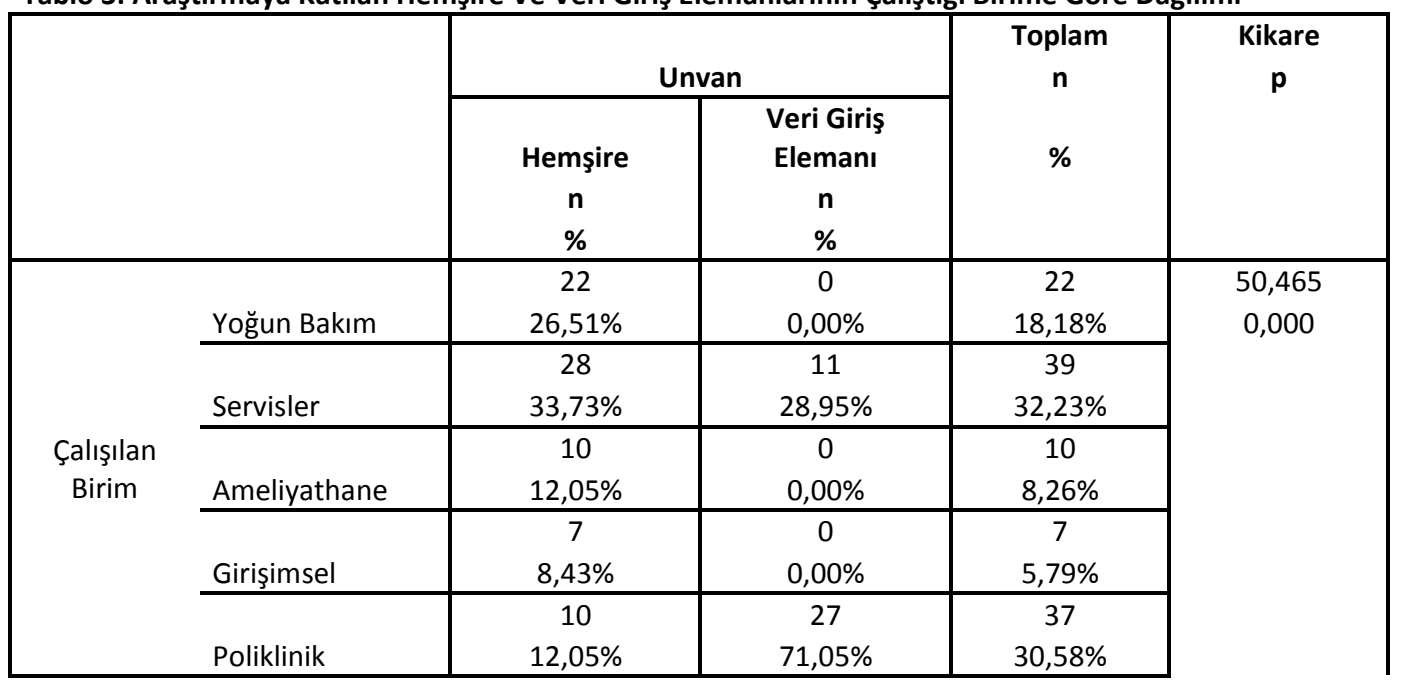




\begin{tabular}{|c|c|c|c|}
\hline Acil & $\begin{array}{c}4 \\
4,82 \% \\
\end{array}$ & $\begin{array}{c}0 \\
0,00 \% \\
\end{array}$ & $\begin{array}{c}4 \\
3,31 \% \\
\end{array}$ \\
\hline İdari Birimler & $\begin{array}{c}2 \\
2,41 \%\end{array}$ & $\begin{array}{c}0 \\
0,00 \%\end{array}$ & $\begin{array}{c}2 \\
1,65 \%\end{array}$ \\
\hline Toplam & $\begin{array}{c}83 \\
100,00 \%\end{array}$ & $\begin{array}{c}38 \\
100,00 \%\end{array}$ & $\begin{array}{c}121 \\
100,00 \%\end{array}$ \\
\hline
\end{tabular}

Araştırmaya katılan hemşirelerin \%33,73'ü servislerde, veri giriş elemanlarının \%71,05’ı polikliniklerde çalışmaktadır (Tablo 3).

\section{2. Hastane Otomasyon Sisteminin Çalışanlar Açısından Algılanması Ölçeği ile Ilgili Veriler}

Araştırmaya katılanların hemşire ve veri giriş görevlilerinin "Hastane Otomasyon Sisteminin Çalışanlar Açısından Algılanması" ölçeğinden aldıkları puanları arasındaki fark anlamlı bulunmuştur $(p<0,005)$. Veri giriş görevlilerinin puanı anlamlı olarak yüksektir. Hipotezimizin aksine ünvanlardan veri giriş elemanları açısından anlamlı fark olduğu görülmüştür ( Tablo 4)

Tablo 4: Araştırmaya Katılanların “Hastane Otomasyon Sisteminin Çalışanlar Açısından Algılanması” Ölçeğinden Aldıkları Puanların Dağılımı

\begin{tabular}{|l|c|c|c|c|c|}
\hline & $\mathrm{n}$ & Ortalama \pm ss & Min & Max & $\mathrm{p}$ \\
\cline { 1 - 4 } Hemşire & 83 & $2,82 \pm 11,17$ & -27 & 29 & \multirow{2}{*}{0,002} \\
\hline Veri giriş Elemanı & 38 & $9,47 \pm 10,49$ & -19 & 26 & \\
\hline Toplam & 121 & $8,40 \pm 12,11$ & 3 & 29 & \\
\hline
\end{tabular}

Araştırmaya katılanların "Hastane Otomasyon Sisteminin Çalışanlar Açısından Algılanması” ölçeğinden aldıkları puanların yaşa göre dağılımında; aldıkları puanları arasındaki fark anlamlı bulunmamıştır. ( $p>0,005)$ ( Tablo 5).

Tablo 5: Araştırmaya katılanların “Hastane Otomasyon Sisteminin Çalışanlar Açısından Algılanması” Ölçeğinden Aldıkları Puanların Yaşa Göre Dağılımı

\begin{tabular}{|l|c|c|c|c|c|}
\hline \multicolumn{1}{|c|}{ Yaş } & $\mathrm{n}$ & Ortalama & SD & Ki-kare & $\mathrm{p}$ \\
\cline { 1 - 3 } $45-54$ ve üzeri & 20 & 72,43 & 2 & 3,444 & 0,179 \\
\cline { 1 - 2 } $35-44$ & 66 & 56,77 & & & \\
\cline { 1 - 3 } $25-34$ & 32 & 57,06 & & & \\
\hline Toplam & 118 & & & & \\
\hline
\end{tabular}

Araştırmaya katılanların "Hastane Otomasyon Sisteminin Çalışanlar Açısından Algılanması” ölçeğinden aldıkları puanların cinsiyete göre dağılımında; aldıkları puanları arasındaki fark anlamlı bulunmamıştır. (p>0,005)( Tablo 6).

Tablo 6: Araştırmaya Katılanların “Hastane Otomasyon Sisteminin Çalışanlar Açısından Algılanması” Ölçeğinden Aldıkları Puanların Cinsiyete Göre Dağılımı

\begin{tabular}{|c|c|c|c|}
\hline Cinsiyet & $\mathbf{n}$ & Ortalama & p \\
\hline Kadın & 110 & $4,47 \pm 11,22$ & 0,182 \\
\hline Erkek & 11 & $9,27 \pm 12,30$ & \\
\hline
\end{tabular}

Tablo 7: Araştırmaya Katılanların “Hastane Otomasyon Sisteminin Çalışanlar Açısından Algılanması” Ölçeğinden Aldıkları Puanların Mezuniyete Göre Dağılımı

\begin{tabular}{|c|c|c|c|c|c|}
\hline & $\mathrm{n}$ & Ort $\pm s s$ & Minimum & Maximum & $\mathrm{p}$ \\
\hline Lise Mezunu & 27 & $11,00 \pm 8,54$ & $-8,00$ & 22,00 & \multirow[t]{4}{*}{0,005} \\
\hline Ön Lisan Mezunu & 41 & $2,37 \pm 10,65$ & $-19,00$ & 26,00 & \\
\hline Lisans Mezunu & 53 & $3,77 \pm 12,16$ & $-27,00$ & 29,00 & \\
\hline Toplam & 121 & $4,91 \pm 11,35$ & $-27,00$ & 29,00 & \\
\hline
\end{tabular}


Tablo 8. Araştırmaya Katılanların “Hastane Otomasyon Sisteminin Çalışanlar Açısından Algılanması” Ölçeğinden Aldıkları Puanların Mezuniyete Göre Gruplar Arası Fark Dağılımı

\begin{tabular}{|c|l|c|c|c|}
\hline \multicolumn{1}{|c|}{ Öğrenimdurumu } & \multicolumn{1}{c|}{ Öğrenim durumu } & Ortalama & SH & $\mathbf{p}$ \\
\hline \multirow{2}{*}{ Lise Mezunu* } & Ön Lisan Mezunu & $8,63415^{*}$ & 2,71163 & 0,005 \\
\cline { 2 - 5 } & Lisans Mezunu & $7,22642^{*}$ & 2,58687 & 0,017 \\
\hline
\end{tabular}

*Tukey Test

Araştırmaya katılanların "Hastane Otomasyon Sisteminin Çalışanlar Açısından Algılanması" ölçeğinden aldıkları puanların mezuniyete göre dağılımında; aldıkları puanları arasındaki fark anlamlı bulunmuştur $(p<0,005)$. lise mezunlarının ölçekden aldıkları puanların ortalaması diğer gruplardan anlamlı olarak yüksektir( Tablo 8).

Tablo 9: Araştırmaya Katılanların "Hastane Otomasyon Sisteminin Çalışanlar Açısından Algılanması” Ölçeğinden Aldıkları Puanların Hizmet Süresine Göre Gruplar Arası Fark Dağılımı

\begin{tabular}{|c|c|c|c|c|c|}
\hline Hizmet Süresi & $\mathrm{n}$ & Ortalama \pm ss & Minimum & Maximum & $p$ \\
\hline $1-4$ yıl & 55 & $4,91 \pm 11,46$ & $-27,00$ & 29,00 & \multirow[t]{5}{*}{0,687} \\
\hline 5-8 yıl & 37 & $3,51 \pm 11,06$ & $-19,00$ & 22,00 & \\
\hline 9-12 yıl & 19 & $7,42 \pm 12,14$ & $-20,00$ & 28,00 & \\
\hline 13 yıl ve üzeri & 10 & $5,30 \pm 11,15$ & $-18,00$ & 18,00 & \\
\hline Toplam & 121 & $4,91 \pm 11,35$ & $-27,00$ & 29,00 & \\
\hline
\end{tabular}

Araştırmaya katılanların "Hastane Otomasyon Sisteminin Çalışanlar Açısından Algılanması” ölçeğinden aldıkları puanların hizmet süresine göre dağılımında; aldıkları puanları arasındaki fark anlamlı bulunmamıştır ( $p>0,005)$ ( Tablo 9).

Tablo 10: Araştırmaya Katılanların “Hastane Otomasyon Sisteminin Çalışanlar Açısından Algılanması” Ölçeğinden Aldıkları Puanların Toplam Hizmet Süresine Göre Gruplar Arası Fark Dağılımı

\begin{tabular}{|c|c|c|c|c|c|}
\hline $\begin{array}{c}\text { Toplam Hizmet } \\
\text { Süresi }\end{array}$ & $\mathrm{n}$ & Ortalama \pm ss & Minimum & Maximum & $\mathrm{p}$ \\
\hline $1-4$ yıl & 24 & $5,96 \pm 10,44$ & $-14,00$ & 21,00 & \multirow{2}{*}{0,499} \\
\hline $5-8$ yıl & 21 & $8,10 \pm 8,28$ & $-7,00$ & 22,00 \\
\hline $9-12$ yıl & 13 & $3,54 \pm 13,86$ & $-27,00$ & 26,00 \\
\hline 13 yıl ve üzeri & 62 & $4,10 \pm 11,74$ & $-20,00$ & 29,00 \\
\hline Total & 120 & $5,11 \pm 11,18$ & $-27,00$ & 29,00 & \\
\end{tabular}

Araştırmaya katılanların "Hastane Otomasyon Sisteminin Çalışanlar Açısından Algılanması" ölçeğinden aldıkları puanların toplam hizmet süresine göre dağııımında; aldıkları puanları arasındaki fark anlamlı bulunmamıştır ( $p>0,005)($ Tablo 10).

Tablo 11: Araştırmaya Katılanların “Hastane Otomasyon Sisteminin Çalışanlar Açısından Algılanması” Ölçeğinden Aldıkları Puanların Çalışılan Birime Göre Gruplar Arası Fark Dağılımı

\begin{tabular}{|l|c|c|c|}
\hline & $\mathrm{n}$ & Ortalama $\pm s s$ & $\mathrm{p}$ \\
\hline Poliklinik & 37 & $7,87 \pm 10,10$ & 0,057 \\
\hline Servis & 84 & $3,61 \pm 11,69$ & \\
\hline
\end{tabular}

Araştırmaya katılanların "Hastane Otomasyon Sisteminin Çalışanlar Açısından Algılanması" ölçeğinden aldıkları puanların toplam çalışılan birime göre dağııımında; aldıkları puanları arasındaki fark anlamlı bulunmamıştır ( $p>0,005)$ ( Tablo 11). 
Tablo 12: Araştırmaya Katılan Hemşire Ve Veri Giriş Görevlilerinin Soru Bazında Aldıkları Puanların Dağılımı (Min Puan:-2 Mak Puan:2)

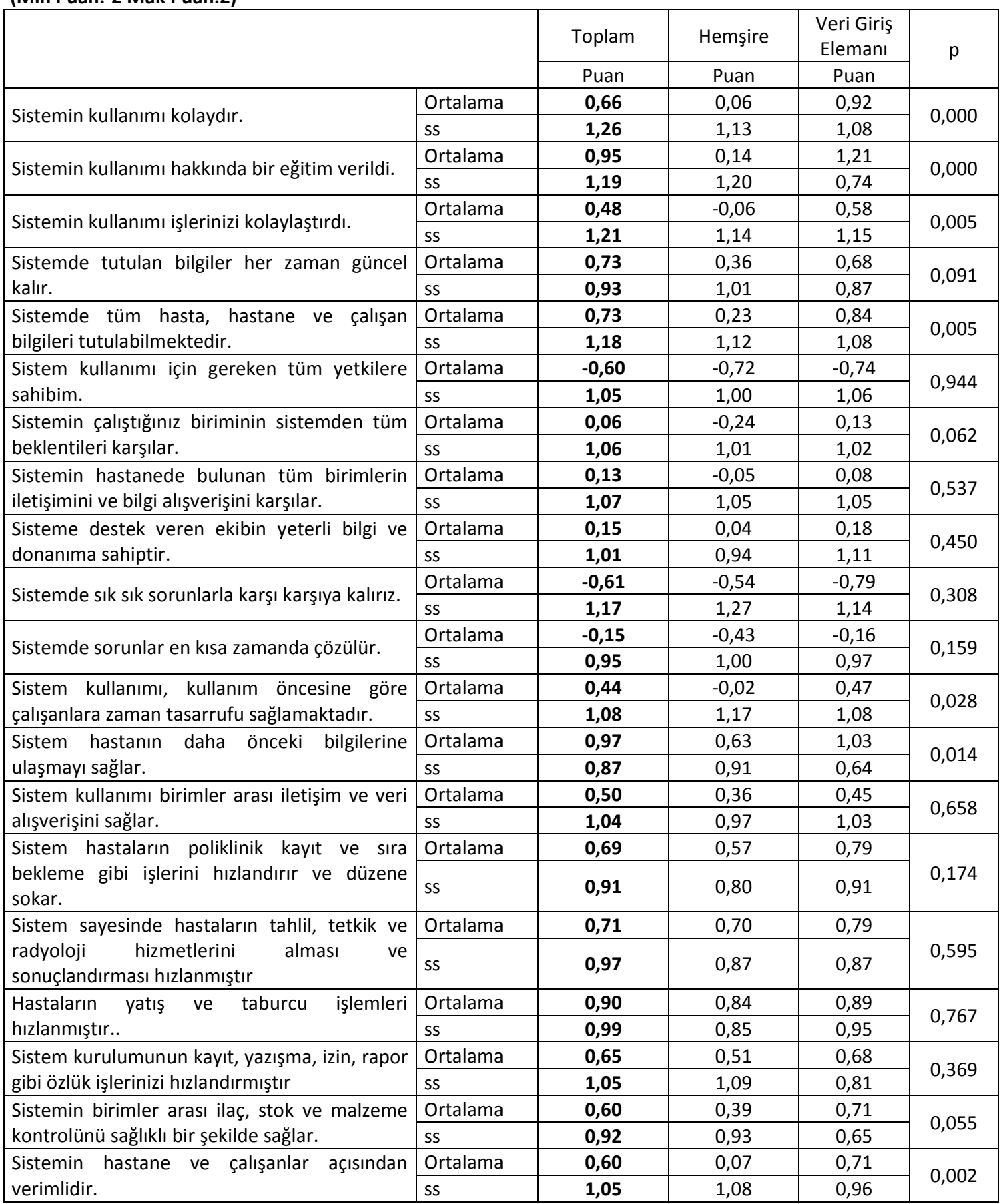

Araştırmaya katılan hemşire ve veri giriş görevlilerinin "Hastane Otomasyon Sisteminin Çalışanlar Açısından Algılanması" ölçeğinden 5 soruya verdikleri cevabın ortama puanı arasındaki farklar anlamlıdır $(p<0,005)$ ( Tablo 12).

Bu sorular:

1. Sistemin kullanımı kolaydır,

2. Sistemin kullanımı hakkında bir eğitim verildi, 
3. Sistemin kullanımı işlerinizi kolaylaştırdı,

4. Sistem kullanımı, kullanım öncesine göre çalışanlara zaman tasarrufu sağlamaktadır,

5. Sistem hastanın daha önceki bilgilerine ulaşmayı sağlar,

6. Sistemin hastane ve çalışanlar açısından verimlidir

sorularıdır. bu altı yargı ifadesine veri giriş görevlileri daha çok katılıılarını ifade ettiği bulunmuştur.

\section{Şekil 1: Araştırmaya Katılanların “Hastane Otomasyon Sisteminin Çalışanlar Açısından Algılanması" Sorularına "Katılma”} Durumu

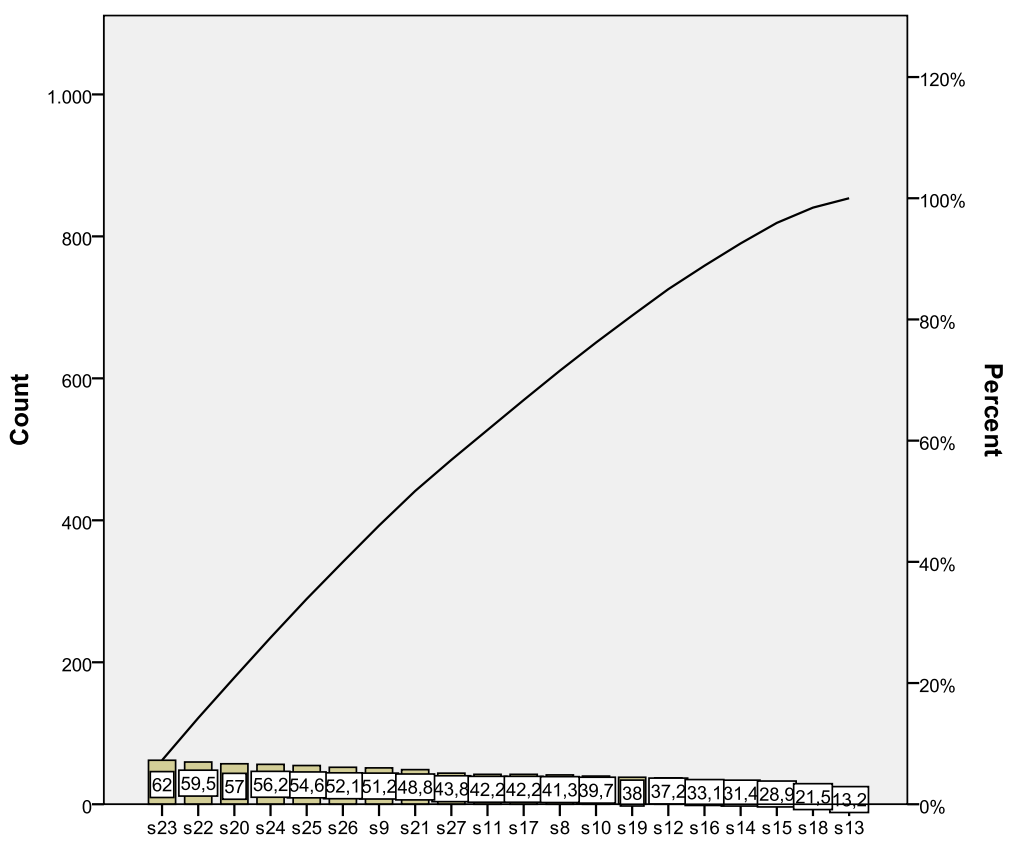

Araştırmaya katılanlar “Hastane Otomasyon Sisteminin Çalışanlar Açısından Algılanması” ölçeğinden;

1. Sistem sayesinde hastaların tahlil, tetkik ve radyoloji hizmetlerini alması ve sonuçlandırması hızlanmıştır (soru 23) $\% 63$ oranda

2. Sistem hastaların poliklinik kayıt ve sıra bekleme gibi işlerini hızlandırır ve düzene sokar (soru 22 ) $\% 59,5$ oranında

3. Sistem hastanın daha önceki bilgilerine ulaşmayı sağlar (soru 20) \%57 oranında

4. Hastaların yatış ve taburcu işlemleri hızlanmıştır (soru 24 ) $\% 56,5$ oranında

5. Sistem kurulumunun kayıt, yazışma, izin, rapor gibi özlük işlerinizi hızlandırmıştır (soru 25) \%54,6 oranında ifadelerine katıldıkları bulunmuştur (Bkz: Şekil 1). 
Şekil 2: Araştırmaya Katılanların “Hastane Otomasyon Sisteminin Çalışanlar Açısından Algılanması” Sorularına "Katılmama" Durumu

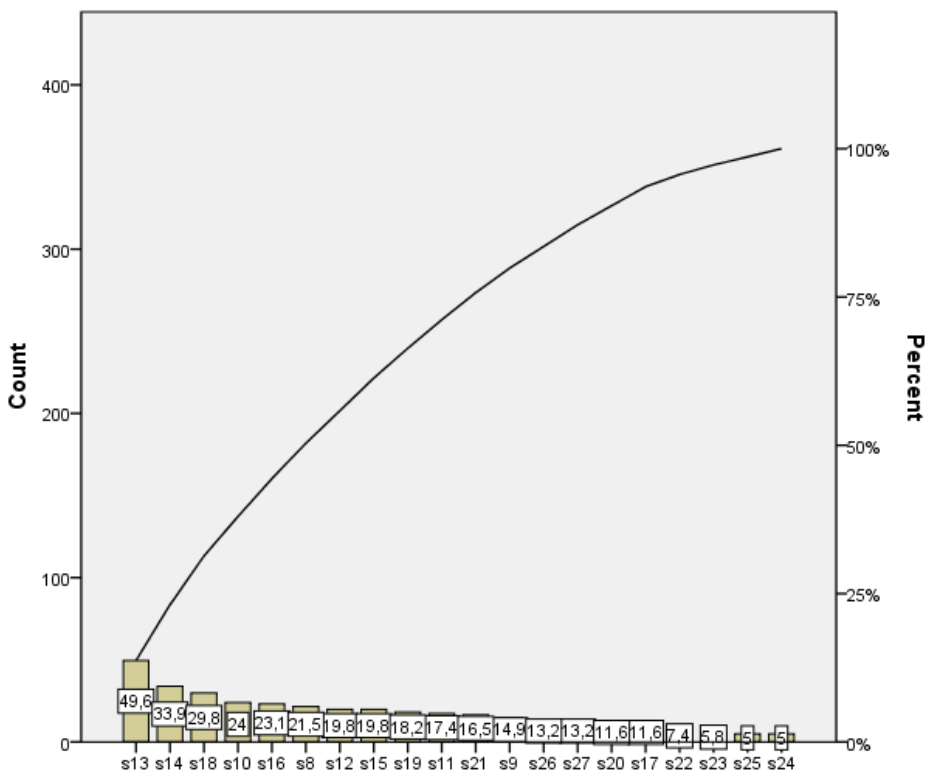

Araştırmaya katılanların "Hastane Otomasyon Sisteminin Çalışanlar Açııından Algılanması" sorularına "katılmama" durumuna bakıldığında;

1. Sistem kullanımı için gereken tüm yetkilere sahibim (soru 13) \%49,6 oranında

2. Sistemin çalıştığınız biriminin sistemden tüm beklentileri karşılar (soru14) \%33,9 oranında

3. Sistemde sorunlar en kısa zamanda çözülür (soru 18) \%29,8 oranında

4. Sistemin kullanımı işlerinizi kolaylaştırdı (soru10) \%24 oranında

5. Sisteme destek veren ekibin yeterli bilgi ve donanıma sahiptir (soru 16) \%23,1 oranında ifadelerine katılmadıkları bulunmuştur(Bkz: Şekil 2).

Hemşirelerin "Hastane Otomasyon Sisteminin Çalışanlar Açısından Algılanması" ölçeğindeki katılmadıkları ilk 5 ifade:

1. Hastaların yatış ve taburcu işlemleri hızlanmıştır.

2. Sistem sayesinde hastaların tahlil, tetkik ve radyoloji hizmetlerini alması ve sonuçlandırması hızlanmıştır

3. Sistem hastanın daha önceki bilgilerine ulaşmayı sağlar.

4. Sistem hastaların poliklinik kayıt ve sıra bekleme gibi işlerini hızlandırır ve düzene sokar.

5. Sistem kurulumunun kayıt, yazışma, izin, rapor gibi özlük işlerinizi hızlandırmıştır. Katılmadıkları ilk 5 ifade:

1. Sistem kullanımı için gereken tüm yetkilere sahibim.

2. Sistemde sık sık sorunlarla karşı karşıya kalırız.

3. Sistemde sorunlar en kısa zamanda çözülür.

4. Sistemin çalıştığınız biriminin sistemden tüm beklentileri karşılar

5. Sistemin kullanımı işlerinizi kolaylaştırdı.

Veri giriş görevlilerinin; Hemşirelerin "Hastane Otomasyon Sisteminin Çalışanlar Açısından Algılanması" ölçeğindeki katıldıkları ilk 5 ifade:

1. Sistemin kullanımı hakkında bir eğitim verildi

2. Sistem hastanın daha önceki bilgilerine ulaşmayı sağlar.

3. Sistemin kullanımı kolaydır.

4. Hastaların yatış ve taburcu işlemleri hızlanmıştır.

5. Sistemde tüm hasta, hastane ve çalışan bilgileri tutulabilmektedir. 
Katılmadıkları ilk 5 ifade:

1. Sistemde sık sık sorunlarla karşı karşıya kalırız.

2. Sistem kullanımı için gereken tüm yetkilere sahibim.

3. Sistemde sorunlar en kısa zamanda çözülür.

4. Sistemin hastanede bulunan tüm birimlerin iletişimini ve bilgi alışverişini karşılar.

5. Sistemin çalıştı̆̆ınız biriminin sistemden tüm beklentileri karşılar.

\section{SONUÇ}

Çalışmamızın sonucunda hemşireler;

1. Hemşireler sistem kullanımı için gereken tüm yetkilere sahip olmadıkları,

2. Sistemde sık sık sorunlarla karşı karşıya kaldığını,

3. Sorunların en kısa zamanda çözülmediğini,

4. Sistemin çalıştığı biriminin sistemden tüm beklentilerini karşılamadığını ve sistemin işlerini kolaylaştırmadığı

5. Sistem kullanma ile ilgili eğitim almadıkları sonuçlarına ulaşılmıştır.

Çalışmamızın sonucunda veri giriş elemanları;

1. Sistemde sık sık sorunlarla karşı karşıya kaldıkları,

2. Sistem kullanımı için gereken tüm yetkilere sahib olmadıkları,

3. Sistemde sorunlar en kısa zamanda çözülemediği,

4. Sistemin hastanede bulunan tüm birimlerin iletişimini ve bilgi alışverişini karşılamadığı,

5. Sistemin çalıştığı biriminin sistemden tüm beklentileri karşılamadığı,

6. Sistem kullanma ile ilgili eğitim aldıkları sonuçlarına ulaşılmıştır.

Her iki grup da bilgi işlemin sistemin hasta işlemleri, laboratuar işlemleri gibi işlemler için faydalı olduğunu ifade etmiştir.

Çalışma sonucu değerlendirildiğinde;

1. Hemşire ve veri giriş elemanlarına gerekli tüm yetkilerin verilmesi gerektiği,

2. Sistemden kaynaklanan sorunların sık sık yaşandığı bu sorunların çözülmesi için hastane bilgi işlem servisinin daha iyi eğitim almış personelden oluşturulması gerektiği,

3. Sistemle ilgili eğitim almamış olan personele hastane yönetimi tarafından hizmetiçi eğitim verilmesi gerektiği,

4. Sistemin personelin çalıştığı biriminin sistemden tüm beklentilerini karşılamadığı hastane yönetiminin çalışılan birimin sistemden beklentilerini belirleyerek sistem üzerinde gerekli düzenlemelerin yapılması gerektiği,

5. Sistemin hastanede bulunan tüm birimler arasındaki iletişimi ve bilgi alış verişini sağlayacak şekilde düzenlenmesi gerektiği görülmektedir.

SBS kalitesini artırmak ve SBS kullanıcılarının farklı beklenti, taleplerini karşılamak için rehberler hazırlanabilir. SBS'nin geliştirilmesi, uygulanması ve bakım aşamasında maliyet, uygulama zamanı, kullanıcı katılımı ve kullanıcı memnuniyetini ölçmek için test edebilebilirlik oldukça önemlidir. Kullanıcılar, eğitim ve teknik personel tarafından desteklenme ağının iyi çalışması gelecekte uygun SBS'ler geliştirme metodolojisi ve uygulanması için uygun olacaktır. 


\section{KAYNAKLAR}

1. Altın F. G., (2008). Sağlık Sektöründe Bilgi Teknolojilerinin Uygulanması: İzmir Örneği Süleyman Demirel Üniversitesi Sosyal Bilimler Enstitüsü İşletme Anabilim Dalı Yüksek Lisans Tezi Isparta.

2. Öner F., (2014). Sağlık Bilişimi, Türkiye'de Sağlık Bilgi Enformasyon Sistemleri Ve Dijital Hastaneler Beykent Üniversitesi Sosyal Bilimler Enstitüsü İ̧letme Yönetimi Anabilim Dalı Hastane Ve Sağlık Kurumları Yönetimi Bilim Dalı Yüksek Lisans Tezi İstanbul

3. Akkoç L., Hastane Bilgi Yönetim Sistemi (HBYS)'nin Isparta'da Bulunan Sağı̆ı Kuruluşları Üzerindeki Etkililiğ̈inin Araştırılması, Süleyman Demirel Üniversitesi Sosyal Bilimler Enstitüsü Kamu Yönetimi Anabilim Dalı, Yüksek Lisans Tezi, Isparta

4. MURPHY, G.F., "Computer - Based Patient Record - A Unifying Principle", Edited by Abdelhak, M., Grostick, S., Hanken, M.A., Jacops, E., Health Information Management of a Strategic Resource, W.B. Saunders Company, USA, 1996.

5. Joanne L. Callen, Jeffrey Braithwaite, Johanna I. "Contextual Implementation Model: A Framework for Assisting Clinical Information System Implementations. Journal of the American Medical Informatics Association" 2008;15(2):255-26

6. Saka O. Tıp Bilişimi. Tıp Bilişimi Güz Okulu. 6-10 Ekim 2003

7. Lewis T, Synowiec C, Lagomarsino G, Schweitaer J. "E-health in low- and middle-income countries: findings from the Center for Health Market Innovations. Bull World Health Organ" 2012;90:332-340

8. Detmer DE. "Building the national health information infrastructure for personal health, health care services, public health, and research. BMC Medical Informatics and Decision Making" 2003;3(1):1-12

9. Kwankam SY. "What e-Health can offer". Bulletin of the World Health Organization. Bull World Health Organ 2004;82(10):800-801

10. http://www.e-saglik.gov.tr/belge/1-33811/sagliknet-hakkinda.html

11. http://www.saglik.gov.tr/TR/belge/1-361/web-uygulamalari.html

12. Bal V. "Bilgi Sistemlerinin Sağlik İşletmeleri Performansına Etkilerinin Veri Zarflama Analizi ille Ölçümü: Türkiye'deki Devlet Hastanelerinde Bir Araştırma". Süleyman Demirel Üniversitesi Sosyal Bilimler Enstitüsü Işletme Anabilim Dalı Doktora Tezi. Isparta 2010. sayfa:15

13. Ömürbek N, Altın FG. "Sağlık Bilişim Sistemlerinin Uygulanmasına iliş̧kin Bir Araştırma: İzmir Örneği”. Sosyal Bilimler Dergisi. 2009,19:215-217

14. Ömürbek N., Demirgubuz Öksüz M., Tunca M., Z., Hastanelerdeki Bilişim Sistemlerinden Klinik Bilgi Sistemlerinin Kullanımına Yönelik Bir Araştırma: Denizli Ve Isparta Örneği, Selçuk Üniversitesi iktisadi ve İdari Bilimler Fakültesi Sosyal ve Ekonomik Araştırmalar Dergisi (The Journal of Social and Economic Research) ISSN: 1303 - 8370 / Nisan 2013 / Yıl: 13 / Sayı: 25

15. Özata M, Aslan Ş. “Klinik Karar Destek Sistemleri ve Örnek Uygulamalar”. The Medical Journal of Kocatepe 2004;5: 11 - 17

16. Örengül O. “Hastane Bilgi Sistemeleri”. Medipol Hastanesi. http://www.sabiyap.org/makaleler.php?mak_id=6 Erişim 15.02.2013

17. Çimen M., (2014). Hastane Bilgi Sistemleri Ve Sektörel GZFT Analizi, Dokuz Eylül Üniversitesi Sosyal Bilimler Enstitüsü İşletme Anabilim Dalı Hastane Ve Sağlık Kuruluşları Yönetimi Programı Yüksek Lisans Tezi, İzmir

18. Hülür Ü. “Bilgi Güvenliği ve Sağ||k”. 12 Eylül 2009. http://www.sabiyap.org/makaleler.php?mak_id=18 Erişim 15.02.2013 